\title{
A Method for Optimizing the Allocation of Sea Resources Based on Ecological Environment Protection
}

\author{
Jie $\mathrm{Huo}^{1}$, Yongchao $\mathrm{Tao}^{2}$, Xiangjun $\mathrm{Xu}^{3 *}$ \\ ${ }^{1}$ Business School, Guangzhou College of Technology and Business, Guangzhou 510850, China \\ ${ }^{2}$ Shandong Marine Economic and Cultural Research Institute, Shandong Academy of Social Science, Qingdao 266000, \\ China
}

${ }^{3}$ Economic school, Anyang Normal University, Anyang 455002, China

*to whom all correspondence should be addressed: e-mail: xaynu@hotmail.com

\section{GRAPHICAL ABSTRACT}

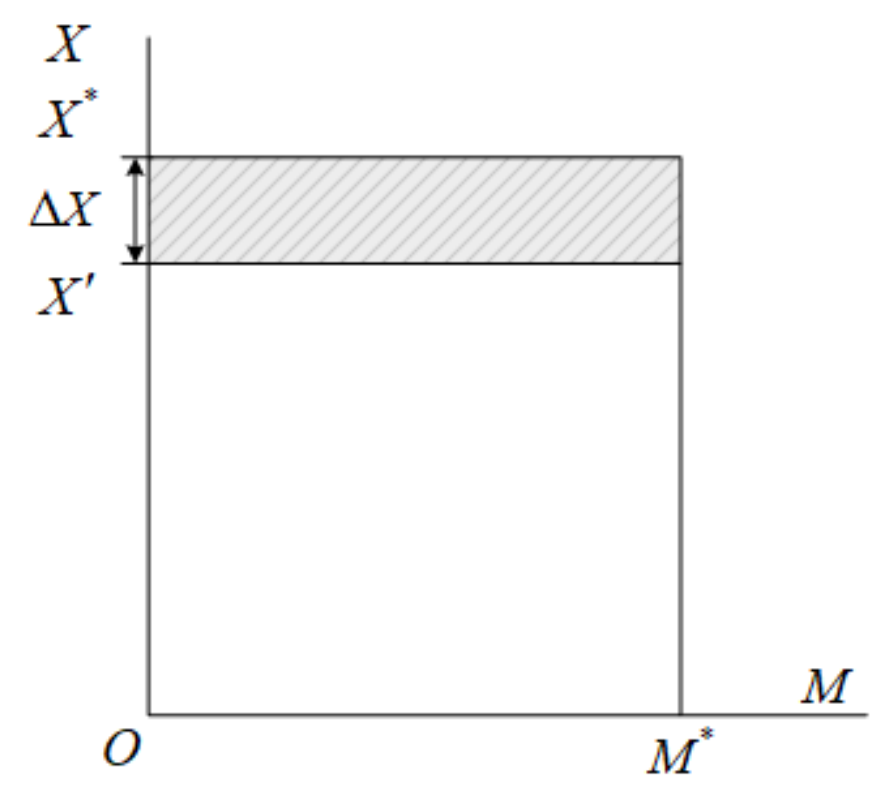

\begin{abstract}
With the increasing demand for marine resources, the marine ecological environment system is gradually destroyed. The traditional allocation of marine resources has been unable to meet the global resource search, resulting in poor distribution uniformity of marine resources and high packet loss rate of resource allocation. Therefore, an optimal allocation method of sea resources based on ecological environment protection is proposed. Based on the concept of ecological protection, this method builds an evaluation index system for the allocation of Marine resources by measuring the loss of Marine spatial resource assets, and calculates the evolution trend and coordination of Marine ecology according to the weight of evaluation index. A robust optimization method for the optimal allocation of sea resources is established by obtaining the spatial differences in the allocation of sea resources. The experimental results show that the proposed method is more uniform in the distribution of sea resources and has a lower packet loss rate.
\end{abstract}


Keywords: Ecological and environmental protection, maritime resources, optimize configuration, asset loss measure, spatial differences.

\section{Introduction}

In the history of human development, mankind's demand for Marine natural resources is unlimited. In a certain time and space, the total amount of resources is limited. This relative finitude of resources interacts with the absolute growth of human needs. It leads to the scarcity of Marine natural resources and affects the health of ecological environment. Due to the scarcity and externality of resources, the allocation of resources should be considered comprehensively. Resource allocation refers to the combination relationship between resources and between resources and other economic factors, as well as the different USES of resources. The distribution among different users and the structural arrangement in terms of time, space, industry, etc. To study the allocation of resources, that is, to study who decides the allocation of resources, to whom and how to allocate resources. The effective allocation of resources is an important research object of economics and the core content of microeconomics. Reasonable resource allocation should not only meet the needs of people's production and life, but also make the limited resources get the fullest and reasonable use (Drews et al., 2018).

Resource allocation has the following characteristics: First, the root cause of resource allocation is resource scarcity. If the reserves of resources are large enough to meet the unlimited demand of resources, the allocation of resources is not necessary. In practice, resources are often limited. On the one hand, the objects themselves are limited for a certain period of time; On the other hand, the technical conditions for the production of goods are limited, and the human life is also limited, this choice is the allocation of resources. Second, the rational allocation of resources is the fundamental problem that must be solved in economic activities. The basic goal of the rational allocation of resources is according to the economic and technological conditions. Reasonable combination of resource elements, reasonable allocation of time, reasonable distribution of space, and reasonable adjustment among industries. Make full use of resources to maximize the overall benefit of resource output and meet the growing social needs. Third, resource allocation should not only follow the basic principles of economics, but also follow economic, ecological and social benefits. Must according to certain goal and follow the principle such as sustainable utilization. To achieve the overall goal of the optimization and sustainable use of natural resources. Fourth, resource allocation is also a political and economic issue (Chen et al., 2017). Behind the allocation of resources, it firstly reflects who has the power to decide the allocation of resources, and secondly reflects what means different interest groups take to influence the decision of resource allocation. Finally, it also reflects the impact of the results of resource allocation on different interest groups. Fifth, resource allocation is closely related to economic system. Because the vast majority of resources are actually scarce or relatively scarce, resource allocation is a problem that any kind of social production will face. However, under the three economic systems of planned economy, market economy and mixed economy, there are great differences in the principles, methods and systems of resource allocation. At present, the allocation of resources in the market economy system is relatively effective, but the allocation of resources is still inseparable from the administrative allocation, this correlation will continue (Zuo et al., 2020). It is the premise of studying the method of marine resources allocation to study the basic theory of marine resources allocation. The basic theory of sea resources allocation includes the concept, characteristics, methods, subjects, objects, objectives and essence of sea resources allocation. There are two ways to allocate sea area resources: administrative allocation and market allocation. The goal is divided into direct goal and final goal, which is essentially the benefit distribution relationship of scarce resources in the whole society (Luciano et al., 2018). 
As the allocation of sea resources belongs to the basic category of sea area use management, the allocation of sea area resources also directly serves the needs of sea area use management. The traditional method of resource allocation is based on the basic theory of sea area resource allocation. The resource allocation framework is designed to realize the allocation of sea area resources by one-to-one matching of sea area events and resource reserves. However, the matching relationship between sea area events and resource reserves under this method is irreplaceable and cannot meet the regional resource allocation under the protection of ecological environment. In view of this problem, an optimal allocation method of sea resources based on ecological environment protection is proposed (Yu et al., 2020). By considering the influence factors of the whole area, this method makes the dynamic allocation method and realizes the reasonable and scientific allocation of sea area resources.

\section{A method for optimizing the allocation of sea resources based on ecological environment protection}

\subsection{Measure the loss of Marine space resource assets}

The method of optimizing the allocation of sea resources is studied. The first step is to calculate the measure of the loss of Marine space resource assets according to the cause of the loss of the value of Marine space resource assets. The value of Marine space resource assets can be calculated by using formula (1):

$$
A_{p}=\sum_{i=1}^{n} x_{i} m_{i}
$$

In the formula: $A_{p}$ represents the total value of Marine space resource asset $p ; x_{i}$ represents the unit

value of a Marine space $i$ resource asset; $m_{i}$ represents the number of resource assets of a certain ocean space $i ; n$ is the number of measurements. According to the above formula, the value measurement of Marine space resource assets can be summarized into two aspects: Unit value $X$ and quantity $M$. The above formula can be summarized as:

$$
A_{p}=X M
$$

Therefore, the loss of Marine space resource assets can be attributed to these two aspects. The reason of unit value is the decrease of the quality of Marine space resource assets or the problem of operation mode, which leads to the decrease of unit value of Marine space resource assets (Zhang et al., 2018). The reasons for this loss of resources are as follows: Pollution results in the decline of the quality of marine space resource assets, and the illegal operation of the use of space resource assets leads to the failure to fully reflect its value and so on. This is shown in Figure 1. For some reason, the unit value of Marine resource assets is reduced from $X^{*}$ to $X^{\prime}$, and the unit value generated is reduced to $\Delta X$. 


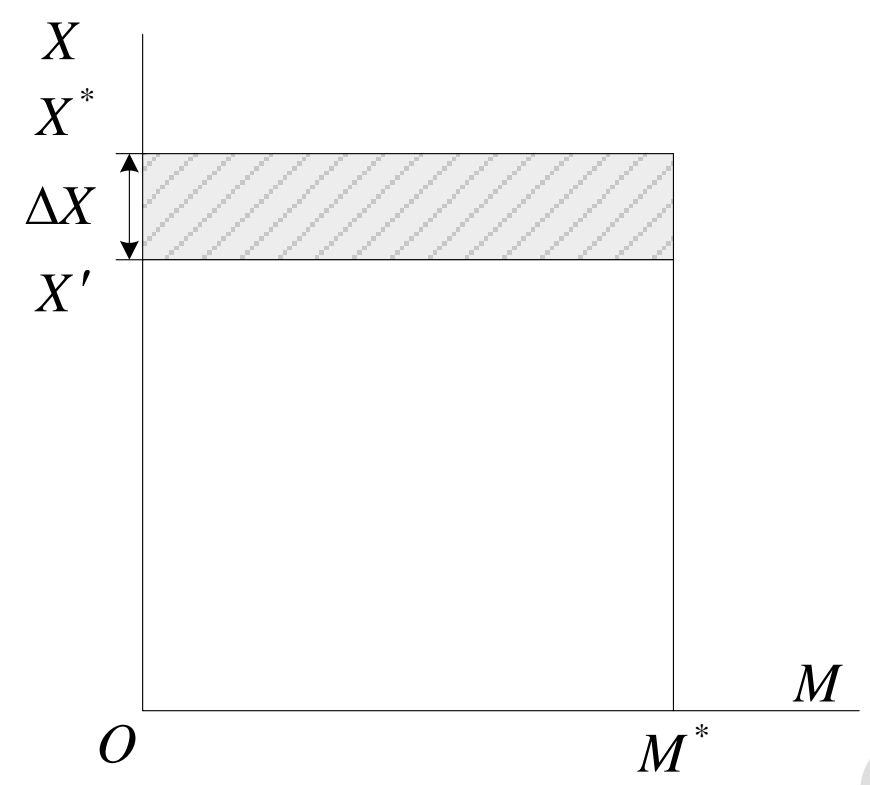

Figure 1. Value loss of marine space resource assets caused by unit value drivers

Because of the loss of asset value caused by unit value factor, according to formula (2), the following formula can be used for measurement:

$$
K_{p}=\Delta X \cdot M^{*}
$$

In the type: $M^{*}$ is the total amount of Marine space resource assets. The quantitative agent refers to the value loss caused by the decrease in the quantity of Marine space resource assets (Wen et al., 2019). The reasons for the decrease are as follows: Unclear definition of property rights leads to loss of national assets; Illegal appropriation of state-owned resource assets; Force majeure leads to a reduction in quantity and so on. As shown in Figure 2. The amount of Marine resource assets decreased from $M^{*}$ to $M^{\prime}$, and the decrease in quantity was $\Delta M$.

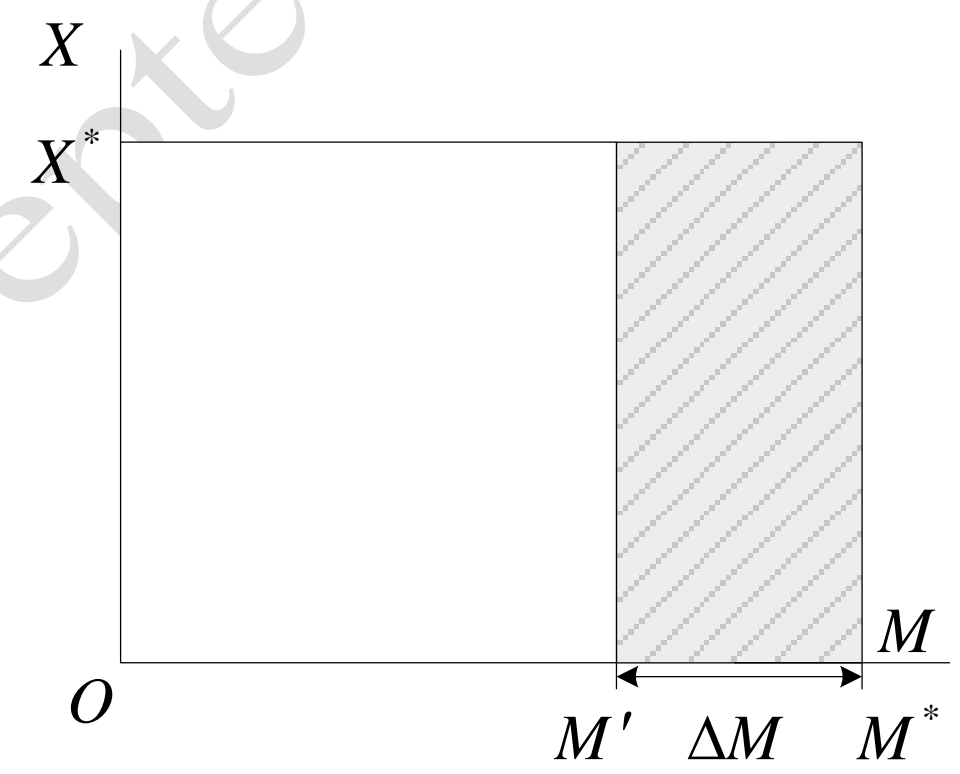

Figure 2. Loss of value of marine space resource assets caused by quantitative drivers

According to the parameter change state shown in Figure 2, according to formula (2). To calculate the measure of asset value loss, the calculation expression is as follows: 


$$
K_{p}=X^{*} \cdot \Delta M
$$

Combined with the above two aspects of the analysis, combined with formula (3-4). The mixed causes of value loss of Marine space resource assets were analyzed (Ojaveer et al., 2018). Generally speaking, the loss of Marine space resource assets has both a decrease in unit value and a decrease in quantity, as shown in Figure 3.

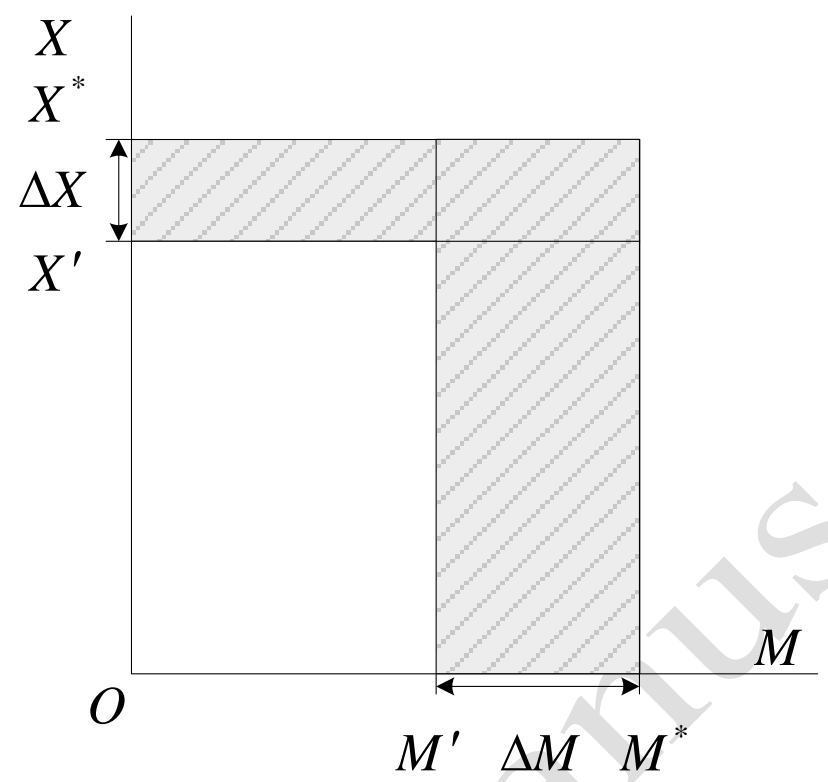

Figure 3. Loss of value of marine space resource assets caused by mixed drivers

According to Figure 3, when the unit value decreases $\Delta X$, the quantity decreases $\Delta M$, and the value loss is:

$$
\Delta A=\Delta X \cdot M^{*}+X^{*} \cdot \Delta M-\Delta X \cdot \Delta M
$$

In the formula, $\Delta A$ represents the amount of value loss of Marine space resource assets. Based on the above analysis, the following generalized multi-factor econometric model can be established for the value loss of ocean space resources:

$$
K_{p}=\sum_{i=1}^{n} X_{i} \Delta M_{i}+\sum_{j=1}^{n} \Delta X_{i} M_{j}-\sum_{i=1, j=1}^{n} \Delta X_{i} \Delta M_{j}
$$

In the type: $X_{i}$ represents the unit value of Marine space resource assets; $\Delta X_{i}$ represents the change in the value of Marine space resource assets; $M_{j}$ represents the amount of Marine space resource assets; $\Delta M_{j}$ represents the variation in the amount of ocean space resources. Where $i=1,2, \ldots, n, j=1,2, \ldots, n, i$ and $j$ represent the types and corresponding quantities of Marine space resource assets (Kalpana and Ramesh, 2018).The above formula is used to measure the loss of Marine space resource assets and provide a new influence parameter value for the optimal allocation of Marine resources.

\subsection{The determination of evaluation index weight}

Based on the above calculation results, the evaluation index system of sea area resource allocation is constructed, and the weight of sea area resource allocation evaluation index is determined. The selection of evaluation indexes should be based on the principles of systematicness, comprehensiveness, scientificity, purposefulness, hierarchy, independence, comparability and dynamics. By following the above principles 
and combining with the measurement results of formula (5), the data in Table 1 are obtained, and the evaluation index system of sea area resource allocation is obtained (Roberto et al., 2018).

Table 1. Evaluation index system of sea area resource allocation

\begin{tabular}{|c|c|c|c|}
\hline \multirow{2}{*}{$\begin{array}{c}\text { Serial } \\
\text { number }\end{array}$} & \multirow{2}{*}{ First level index } & \multicolumn{2}{|c|}{ Two level index } \\
\hline & & Index content & Quantitative index \\
\hline a1 & $\begin{array}{l}\text { Social benefit } \\
\text { index-A }\end{array}$ & Impact on Stakeholders-A1 & $\begin{array}{c}\text { Very large, large, average, small and } \\
\text { very small }\end{array}$ \\
\hline $\mathrm{a} 2$ & & Impact on sea related sectors-A2 & $\begin{array}{c}\text { Very large, large, average, small and } \\
\text { very small }\end{array}$ \\
\hline a3 & & Expected employment level-A3 & Number of Posts \\
\hline a4 & & $\begin{array}{l}\text { Influence degree of landscape } \\
\text { function-A4 }\end{array}$ & $\begin{array}{c}\text { Very large, large, average, small and } \\
\text { very small }\end{array}$ \\
\hline a5 & & Public service level-A5 & $\begin{array}{c}\text { Very large, large, average, small and } \\
\text { very small }\end{array}$ \\
\hline a6 & & Intensive control level-A6 & $\begin{array}{l}\text { Very large, large, average, small and } \\
\text { very small }\end{array}$ \\
\hline b1 & $\begin{array}{l}\text { Economic } \\
\text { benefits } \\
\text { indicators-B }\end{array}$ & Total expected income-B1 & $\begin{array}{l}\text { salary+welfare+depreciation+labor, } \\
\text { unemployment insurance+product sales } \\
\text { tax and surcharges+VAT payable+ } \\
\text { business surplus }\end{array}$ \\
\hline b2 & & Income from sea area use fund-B2 & $\begin{array}{l}\text { Sea area of the project*Collection } \\
\text { standard of sea area use fee*Use sea } \\
\text { term }\end{array}$ \\
\hline b3 & & Expected output per unit area-B3 & Expected revenue from sea use/Sea area \\
\hline b4 & & Input output ratio-B4 & $\begin{array}{c}\text { Expected revenue from sea use/Total } \\
\text { investment }\end{array}$ \\
\hline b5 & & Unit shoreline output value-B5 & $\begin{array}{l}\text { Expected revenue from sea use/Length } \\
\text { of shoreline used }\end{array}$ \\
\hline b6 & & Tax level-B6 & $\begin{array}{l}\text { Total tax amount of configuration } \\
\text { object }\end{array}$ \\
\hline b7 & & $\begin{array}{l}\text { Promote the progress of science and } \\
\text { technology-B7 }\end{array}$ & $\begin{array}{c}\text { Very large, large, average, small and } \\
\text { very small }\end{array}$ \\
\hline $\mathrm{c} 1$ & $\begin{array}{c}\text { Resource and } \\
\text { environment } \\
\text { benefit index-C }\end{array}$ & $\begin{array}{l}\text { Ratio of occupied shoreline to } \\
\text { regional shoreline-C1 }\end{array}$ & $\begin{array}{l}\text { Occupation of shoreline/Regional } \\
\text { shoreline }\end{array}$ \\
\hline c2 & & $\begin{array}{l}\text { Ratio of formed shoreline to } \\
\text { occupied shoreline-C2 }\end{array}$ & $\begin{array}{c}\text { Shoreline formation/Occupation of } \\
\text { shoreline }\end{array}$ \\
\hline $\mathrm{c} 3$ & & Loss of biological resources-C3 & $\begin{array}{l}\text { Loss of biological resources*Unit price } \\
\text { of currency }\end{array}$ \\
\hline $\mathrm{c} 4$ & & $\begin{array}{l}\text { Environmental protection } \\
\text { investment amount-C4 }\end{array}$ & $\begin{array}{l}\text { Investment in environmental protection } \\
\text { facilities+Operation cost of } \\
\text { environmental protection facilities }\end{array}$ \\
\hline $\mathrm{c} 5$ & & $\begin{array}{c}\text { Impact degree of ecological } \\
\text { environment-C5 }\end{array}$ & $\begin{array}{c}\text { Very large, big, average, small and very } \\
\text { small }\end{array}$ \\
\hline c6 & & Sea area renovation and restoration & Very effective, effective, general, \\
\hline
\end{tabular}




\begin{tabular}{|c|c|c|c|}
\hline & & capacity-C6 & ineffective and extraordinary difference \\
\hline $\mathrm{d} 1$ & $\begin{array}{c}\text { Other } \\
\text { indicators-D }\end{array}$ & $\begin{array}{c}\text { Consistency with laws and } \\
\text { regulations-D1 }\end{array}$ & Consistent and inconsistent \\
\hline $\mathrm{d} 2$ & & $\begin{array}{l}\text { Compliance with technical } \\
\text { standards, specifications and } \\
\text { plans-D2 }\end{array}$ & Conformity and non conformity \\
\hline $\mathrm{d} 3$ & & $\begin{array}{l}\text { Disaster prevention and mitigation } \\
\text { level-D3 }\end{array}$ & Very high, high, average, low, very low \\
\hline $\mathrm{d} 4$ & & Loan repayment ability-D4 & Very high, high, average, low, very low \\
\hline $\mathrm{d} 5$ & & $\begin{array}{c}\text { The rationality of supervision and } \\
\text { management-D5 }\end{array}$ & $\begin{array}{l}\text { Very reasonable, reasonable, general, } \\
\text { unreasonable, very not reasonable }\end{array}$ \\
\hline
\end{tabular}

According to the technical guidelines for the demonstration of the use of sea areas and the technical guidelines for the assessment of the environmental impact of Marine engineering, different sea areas have different ways of using the sea (Liu et al., 2019). Even if it is the same type of use of the sea, its subordinate use of the sea is different. This practical problem seriously affects the stability of index weight and the uncertainty of index weight value greatly affects the effect of allocation of sea area resources. In the actual management of sea areas, the weight value of an evaluation index in different sea USES is different, and there are many uncertain factors that are difficult to quantify. Therefore, expert grading method and analytic hierarchy process are adopted. According to the evaluation index system of sea area resource allocation in Table 1, the weight value of sea area resource allocation evaluation index is re-determined (Viktor and Larisa, 2019). The specific steps are as follows:

Firstly, the index weight of sea area resource allocation is designed, the consultation table is determined, and the experts' opinions are consulted anonymously; Analyze and summarize the opinions of experts, and timely feedback the statistical situation to the experts participating in the evaluation, and the experts can modify their own opinions; After many rounds of anonymous consultation and feedback. Then the analytic hierarchy process is used to form the contrast matrix.

Now on the target layer. Namely sea area resources carry on the criterion layer division. The results of division include four contents in Table 1: Social benefits $A$, economic benefits $B$, resource and environmental benefits $C$, other benefits $D$; The above four aspects are further refined according to Table 1. On the analytic hierarchy process (ahp) to determine weight, first is the first level indicators, were determined $A, B, C, D$ four primary index weights. They are $\omega_{1}, \omega_{2}, \omega_{3}$ and $\omega_{4}$ respectively.

Grade one index $\omega_{1}+\omega_{2}+\omega_{3}+\omega_{4}=1$. Secondly, the indicators of the second level are determined as follows:

$$
\left\{\begin{array}{l}
\omega_{A 1}+\omega_{A 2}+\omega_{A 3}+\omega_{A 4}+\omega_{A 5}+\omega_{A 6}=1 \\
\omega_{B 1}+\omega_{B 2}+\omega_{B 3}+\omega_{B 4}+\omega_{B 5}+\omega_{B 6}+\omega_{B 7}=1 \\
\omega_{C 1}+\omega_{C 2}+\omega_{C 3}+\omega_{C 4}+\omega_{C 5}+\omega_{C 6}=1 \\
\omega_{D 1}+\omega_{D 2}+\omega_{D 3}+\omega_{D 4}+\omega_{D 5}=1
\end{array}\right.
$$

The above formula represents the secondary weight indicators of four primary indicators. For example, in index $A$ of social benefits. Compare $A_{1}-A_{6}$ indicators and establish their respective weights. Set as $k_{1}$, 
$k_{2}, k_{3}, k_{4}, k_{5}, k_{6}$. The weight value of $A_{1}-A_{6}$ can be calculated as:

$$
\left\{\begin{array}{l}
q_{1}=\omega_{A 1} k_{1} \\
q_{2}=\omega_{A 2} k_{2} \\
q_{3}=\omega_{A 3} k_{3} \\
q_{4}=\omega_{A 4} k_{4} \\
q_{5}=\omega_{A 5} k_{5} \\
q_{6}=\omega_{A 6} k_{6}
\end{array}\right.
$$

By analogy, the weight of all secondary indicators is obtained through AHP. And finally determine the specific weight of the secondary indicators as $q_{1}, q_{2}, \ldots, q_{24}$ (Brauner et al., 2018). Thus, the re-confirmation of the weight of the evaluation index of the allocation of sea resources is completed.

\subsection{To obtain the spatial differences in the allocation of resources in sea areas}

Dimensionless index is to calculate the actual value of all indexes according to the original data and weight, and convert it into the value of interval $[0,1]$. In the process of reacquiring the index weight, if the actual value of the index is bigger, the better, it represents a positive index. If the smaller the actual value of the indicator is, the better, it means the negative indicator. Different dimensionless methods are needed for different types of indexes. The following formula is combined with formula (8), the development coordination index of Marine eco-economic system after dimensionless treatment:

$$
\sigma_{i j}=\left\{\begin{array}{l}
\frac{q_{n}\left(z_{i j}-z_{i}^{\min }\right)}{z_{i}^{\max }-z_{i}^{\min }}, \text { Positive indicators } \\
\frac{q_{n}\left(z_{i}^{\max }-z_{i j}\right)}{z_{i}^{\max }-z_{i}^{\min }}, \text { Negative indicators }
\end{array}\right.
$$

In the above equations, $\sigma_{i j}$ is the actual calculated value of the $i$-th index; $z_{i}^{\max }$ and $z_{i}^{\min }$ are the maximum and minimum values of index $i$-th in a measurement period, respectively; $\sigma_{i j}$ represents the evaluation results of the standard values of each indicator (Ye et al., 2020). Combined with the above formula to calculate the structure, the comprehensive evaluation value of the development status of the ocean eco-economic system is calculated:

$$
g=\sum_{l=1}^{u} q_{1 l} \cdot \sum_{m=1}^{v} q_{2 m} \cdot \sum_{i=1}^{w} q_{i} \sigma_{i j}
$$

In the formula: $G$ represents the comprehensive evaluation value of the development and evolution trend of Marine ecological economic system; $q_{l}$ is the weight of indicator system of subsystem $l ; q_{2 m}$ represents the weight of the $m$-th state level indicator system; $q_{i}$ is the evaluation value of the $i$ basic index and $j$ period in the $m$ state layer of subsystem $l ; u, v$ and $w$ are the index volume coefficients of subsystem, the number of state layers of subsystem $l$ and the number of basic indexes in state layer $m$ respectively. According to the evaluation value of each state layer, Marine ecological subsystem, Marine economic subsystem and Marine social subsystem, the comprehensive evaluation value of the development state of 
Marine ecological economic system is obtained. For the change process of interaction stress and evolution of any two subsystems of Marine eco-economic system, it can be regarded as a nonlinear process, and its evolution equation can be expressed as:

$$
\frac{d x(t)}{d t}=h\left(x_{1}, x_{2}, \ldots, x_{n}\right)
$$

In the type: $i=1,2, \ldots, n$ is the order constant; $h$ is a nonlinear function of $x_{i}$. Because the coordination of the motion of the nonlinear system depends on the property of the characteristic roots of the first approximation system. Expand it out by a Taylor series near the origin and remove the higher order term $b\left(x_{1}, x_{2}, \ldots, x_{n}\right)$. The approximate expression of the above evolution equation can be obtained:

$$
\frac{d x(t)}{d t}=\sum_{i=1}^{n} a_{i} x_{i}, i=1,2, \ldots, n
$$

In the formula: $a_{i}$ is the remaining term after the higher order term is removed (Scott et al., 2018). According to the above equation (10-12), a representation function of the development state of any two subsystems of the Marine eco-economic system can be established:

$$
\left\{\begin{array}{l}
h\left(g_{1}\right)=\sum_{s=1}^{n} e_{s} g_{s}, s=1,2, \ldots, m \\
h\left(g_{2}\right)=\sum_{t=1}^{n} f_{t} g_{t}, t=1,2, \ldots, q
\end{array}\right.
$$

$g_{1}$ and $g_{2}$ represent the evaluation indexes of the development state of the two subsystems related to $g$. $e$ and $f$ are the weight of each index. In view of the interaction between the subsystems of Marine eco-economic system, it can be considered as a composite system. Obviously, $h\left(g_{1}\right)$ and $h\left(g_{2}\right)$ can reflect the development and evolution of any two subsystems of the composite system. The third subsystem is not considered. According to the general system theory, the evolution equation expressed by coordination degree can be deduced as follows:

$$
\left\{\begin{array}{l}
F_{1}=\frac{d h\left(g_{1}\right)}{d t}=\lambda_{1} h\left(g_{1}\right)+\lambda_{2} h\left(g_{2}\right), D_{F_{1}}=\frac{d F_{1}}{d t} \\
F_{2}=\frac{d h\left(g_{2}\right)}{d t}=\gamma_{1} h\left(g_{1}\right)+\gamma_{2} h\left(g_{2}\right), D_{F_{2}}=\frac{d F_{2}}{d t} \\
\lambda=\arctan \left(\frac{D_{F_{1}}}{D_{F_{2}}}\right)
\end{array}\right.
$$

In the formula: $F_{1}$ and $F_{2}$ represent the evolution state of any two subsystems of the Marine eco-economic system under the influence of itself and another system $D_{F_{1}} . D_{F_{2}}$ is the evolution speed of two subsystems under the influence of itself and another system; $\lambda_{1}, \lambda_{2}, \gamma_{1}$ and $\gamma_{2}$ respectively represent the interactive stress relation indexes of the two subsystems. It is known that in the Marine eco-economic system, $F_{1}$ and $F_{2}$ affect each other, and the change of any subsystem will lead to the change of the whole composite system. The Bi exponential interaction between the ecosystem subsystems can be represented by 
the interaction curve. Generally, it is a composite function formed by the superposition of a power function and an exponential function, and its expression formula is as follows:

$$
p=F_{1}-F_{2}\left(10^{\frac{\mu-k}{\alpha}}-\hat{p}\right)^{2}
$$

In the formula: $p$ represents the value of spatial difference; $\mu$ represents the degree of ecological deterioration; $k$ represents the level of Marine ecology; $\hat{p}$ is the spatial difference reference (Dillon et al., 2018). By measuring the development trend and coordination of Marine ecology, the spatial differences in the distribution of Marine resources are obtained.

\subsection{Robust optimization of optimal allocation of sea resources based on ecological environment protection}

The previous section analyzed the spatial differences in the dynamic allocation of marine resources. Based on the analysis results of formula (15), a robust optimization method for the optimal allocation of sea resources is established based on the ecological environment protection. In order to improve the performance of the method, the following assumptions are made on the premise of emergency resource allocation of the reserve base: Configuration is relatively difficult, time consuming, and distance distant.

According to the sea area reserve base emergency resources allocation total time and allocation total loss. Measure the timeliness of emergency resources and the allocation loss of emergency resources respectively. Among them: The total time of emergency resource allocation refers to the total time of transportation of all emergency resources transferred from the reserve base to the accident area in the future allocation cycle. Is the product of transportation volume and transportation time of various emergency resources transferred from the reserve base to the accident area, so the unit of total time of emergency resources allocation is ton / hour. The total loss of emergency resource allocation refers to the future allocation cycle. The allocation level of emergency resources in the reserve base is too high, resulting in idle loss of emergency resources and low allocation level of emergency resources. The sum of emergency resource shortage compensation loss. Since the emergency resource shortage loss is more serious than the idle loss, the demand compensation penalty coefficient is introduced to magnify the emergency resource shortage loss. The loss of emergency resources allocation is the product of compensation penalty coefficient and loss of emergency resources allocation, and the idle loss of emergency resources allocation is the idle amount of emergency resources of each reserve base (Dudin et al., 2019).

Set the resource reserve as $Q_{j}$.

The time for $n$-th type of emergency resources to be transported from reserve base $c_{j}$ to accident area $d_{i}$ is $t_{m i j}$; The dynamic demand of type $n$-th emergency resources in the accident area $d_{i}$ is $q_{n i}$; $\tau$ represents the penalty coefficient of compensation demand; The number of emergency resources of type $n$-th allocated by reserve base $c_{j}$ is $\alpha_{m j}$; The number of type $n$-th emergency resources transported from reserve base $c_{j}$ to accident area $d_{i}$ is $\beta_{m i j}$; When the emergency resource demand of type $n$-th in the accident area $d_{i}$ is not met, the compensation amount is $\theta_{m i}$. The core of optimal allocation of sea 
resources based on ecological environment protection is to find the optimal allocation level of emergency resources of each reserve base. Therefore, $\alpha_{m j}$ is the core decision variable. $\beta_{m i j}$ and $\theta_{m i}$ are the volume of emergency resources transferred between the reserve base and the accident area, and the amount of emergency resources compensated in the accident area.

Combined with the above mentioned reserve base emergency resources allocation constraints analysis and configuration model assumptions. The emergency resource allocation mode of reserve base based on ecological environment protection can be constructed, as shown below.

$$
\left\{\begin{array}{l}
\varphi_{1}=\min \sum_{n \in N} \sum_{i \in I} \sum_{j \in J} t_{m i j} \beta_{m i j} \\
\varphi_{2}=\min \sum_{n \in N}\left[\sum_{i \in I} \sum_{j \in J}\left(\alpha_{m j}-\beta_{m i j}\right)+\tau \sum_{i \in I} \theta_{m i}\right]^{s . t .}\left\{\begin{array}{l}
\sum_{n \in N} \alpha_{m j} \leq Q_{j}, \forall j \\
\sum_{i \in I} \beta_{m i j} \leq \alpha_{m j}, \forall m, j \\
\sum_{j \in J} \beta_{m i j}+\theta_{m i} \geq q_{n i}, \forall m, i \\
\alpha_{m j}, \beta_{m i j}, \theta_{m i} \geq 0, \forall m, i, j
\end{array}\right.
\end{array}\right.
$$

In the type: The first objective function $\varphi_{1}$ of the emergency resource allocation model of reserve base is the minimum total time to realize the emergency resource allocation. The second objective function $\varphi_{2}$ achieves the minimum total loss of emergency resource allocation. In the target function $\varphi_{2}$. Item 1 represents the total amount of idle emergency resources allocated by each reserve base during the allocation period and is the difference between the amount of emergency resources allocated by the reserve base and the total amount of emergency resources transported from the reserve base to the accident area. The second term represents the compensation loss of emergency resources in the accident area and is the product of the sum of the compensation amount of emergency resources in each accident area and the compensation penalty coefficient $\tau$, usually the compensation penalty coefficient $\tau>1$.

According to formula (16), it can be seen that the formula contains three uncertain variables: the dynamic demand of emergency resources in the accident area $q_{n i}$, the volume of emergency resources transferred between the accident area and the reserve pool $\beta_{m i j}$, and the compensation amount of emergency resources in the resource reserve base $\theta_{m i}$. Usually, there is a linear correlation between them. The transportation volume and compensation volume of emergency resources change with the change of dynamic demand, and the change trend is consistent. The affine relationship between decision variables and uncertain parameters is called affine function. Therefore, the transportation volume and compensation amount of emergency resources can be expressed as a linear function of demand, as shown below:

$$
\left\{\begin{array}{l}
\beta_{m i j}=\omega_{m i j} q_{n i} \\
\theta_{m i}=\bar{\omega}_{m i} q_{n i}
\end{array} \quad \forall m, i, j\right.
$$

In the type: $\omega_{m i j}$ and $\bar{\omega}_{m i}$ respectively represent the correlation coefficients of the transportation volume of emergency resources and the compensation volume on the dynamic demand, and both are positive, which are non-adjustable variables (Khamse-Ashari et al., 2018). After the above linear transformation, the dynamic demand of emergency resources becomes the only uncertain variable in the configuration mode. Take 
formula (15) into the emergency resource allocation mode (16) of reserve base. The affine corresponding formula of emergency resource allocation mode of reserve base based on environmental protection demand is obtained:

$$
\left\{\begin{array}{l}
\varphi_{1}=\min \sum_{n \in N} \sum_{i \in I} q_{n i}\left(\sum_{j \in J} \omega_{m i j} t_{m i j}\right) \\
\varphi_{2}=\min \sum_{n \in N}\left[\sum_{i \in I} \alpha_{m j}+\sum_{i \in I} q_{n i}\left(\tau \bar{\omega}_{m i}-\sum_{j \in J} \omega_{m i j}\right)\right]
\end{array}\right]^{\text {s.t. }}\left\{\begin{array}{l}
\sum_{n \in N} \alpha_{m j} \leq Q_{j}, \forall j \\
\sum_{i \in I} \omega_{m i j} q_{n i} \leq \alpha_{m j}, \forall m, j \\
\sum_{j \in J} \omega_{m i j}+\bar{\omega}_{m i} \geq 1, \forall m, i \\
\alpha_{m j}, \omega_{m i j}, \bar{\omega}_{m i} \geq 0, \forall m, i, j
\end{array}\right.
$$

The uncertainty variable contained in the model is the dynamic demand of emergency resources $q_{n i}$, which belongs to the category of uncertain optimization due to the existence of ecological environmental protection index. Based on the above analysis and in combination with the symmetry hypothesis, the emergency resource demand $q_{n i}$ of the accident area $d_{i}$ can be expressed as $q_{n i} \in\left(q_{n i}^{0}-\hat{q}_{n i}, q_{n i}^{0}+\hat{q}_{n i}\right), \forall i, m$ by the set, and is the disturbance level of the predicted value of the symmetric bounded closed convex search quantity. The established robust optimization model for optimal allocation of sea resources is as follows:

$$
\left\{\begin{array}{l}
\varphi_{1}=\min \left[\sum_{i \in I} \sum_{n \in N} q_{n i}^{0}\left(\sum_{j \in J} \omega_{m i j} t_{m i j}\right)+\max \left[\sum_{n i \in U} \hat{q}_{n i}\left(\sum_{j \in J} \omega_{m i j} t_{m i j}\right)+\left(\Gamma_{0}-\left|\Gamma_{0}\right|\right) \hat{q}_{r_{0}}\left(\sum_{j \in J} \omega_{r_{0}} t_{r_{0}}\right)\right]\right] \\
\varphi_{2}=\min \left[\sum_{j \in J} \sum_{n \in N} \alpha_{m j}+\sum_{i \in I} \sum_{n \in N} q_{n i}^{0}\left(\tau \bar{\omega}_{m i}-\sum_{j \in J} \omega_{m i j}\right)+\max \left[\sum_{n i \in U} \hat{q}_{n i}\left(\tau \bar{\omega}_{m i}-\sum_{j \in J} \omega_{m i j}\right)+\left(\Gamma_{0}-\left|\Gamma_{0}\right|\right) \hat{q}_{r_{0}}\left(\tau \bar{\omega}_{r_{0}}-\sum_{j \in J} \omega_{r_{0}}\right)\right]\right]
\end{array}\right.
$$

In the type: $\Gamma_{0}$ represents the control parameters of sea area resource demand; $\hat{q}_{r_{0}}$ represents the demand disturbance level under the constraints of ecological and environmental parameters; $\omega_{r_{0}}$ represents the weight of the disturbance index; $t_{r_{0}}$ is the time under the influence. It can be found by analyzing two objective functions of emergency resource allocation in reserve base. The larger the value of control parameter $\Gamma_{0}$ is, the higher the demand disturbance level $\hat{q}_{r_{0}}$ is, and the higher the corresponding emergency resource allocation cost is (De La Fuente et al., 2018).

\section{Experimental results and analysis}

In order to verify the effectiveness of the research method, a comparative experiment was designed. In the experiment. The method of optimal allocation of sea area resources based on uncertainty proposed in Roberto (2018)'s study and the method of optimal allocation of sea area resources based on remote sensing data assimilation proposed in Viktor and Larisa (2019)'s study are used as experimental control methods. The experimental results of this method are compared with those of the proposed method. An area to be optimized in the allocation of sea resources was randomly selected as the experimental test object. The distribution of emergency resource reserve base in this sea area is shown in Figure 4. 


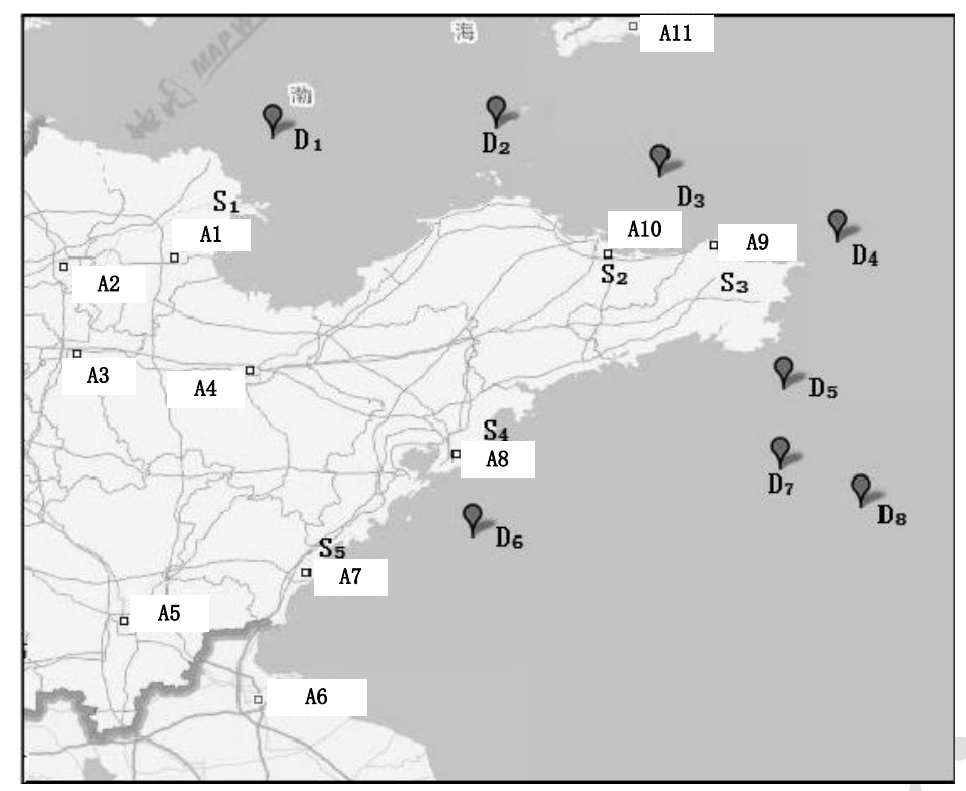

Figure 4. Layout of emergency resource reserve base and accident area center

In the Figure 4, A1-A11 represents the major cities along the coast. S1-S5 represents the resource reserve base; D1-D8 represents the frequent occurrence center of maritime accidents. The location of five emergency resource reserve bases and the coordinate data of eight accident area centers in the maritime jurisdiction of this region were imported into the map software (Khoo et al., 2019). The distance between the emergency resource reserve base of maritime jurisdiction and the accident area center can be obtained by using the distance measurement tool, as shown in Table 2.

Table 2. Distance between emergency resource reserve base and accident area center (unit: Km)

\begin{tabular}{cccccc}
\hline $\begin{array}{c}\text { Accident area } \\
\text { center }\end{array}$ & \multicolumn{5}{c}{ Reserve base } \\
\hline \\
D1 & S1 & S2 & S3 & S4 & S5 \\
D2 & 105 & 215 & 353 & 630 & 745 \\
D3 & 209 & 72 & 205 & 473 & 562 \\
D4 & 322 & 97 & 103 & 386 & 500 \\
D5 & 405 & 165 & 40 & 290 & 383 \\
D6 & 508 & 255 & 72 & 210 & 295 \\
D7 & 702 & 480 & 292 & 50 & 89 \\
D8 & 575 & 355 & 177 & 228 & 305 \\
\hline
\end{tabular}

According to the basic data information in Figure 4 and Table 2. The two methods are respectively used for the allocation of sea area resources. The Figure 5 is the distribution map of emergency resources allocation of different methods. The comparison results are as follows: 


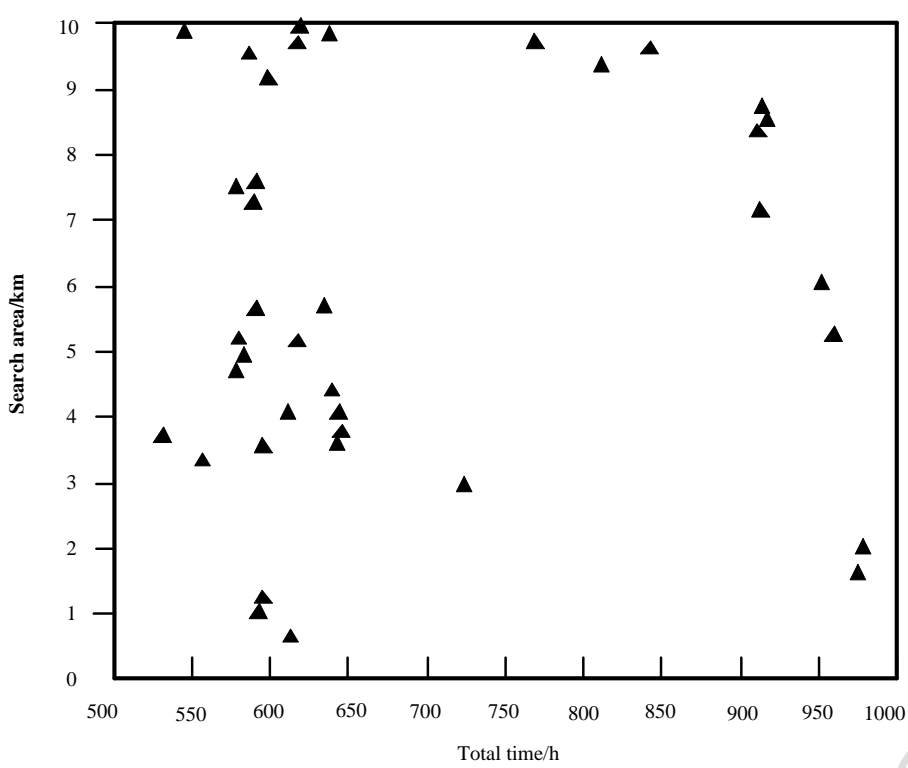

(a) The test results of resource optimal allocation (Roberto et al., 2018)

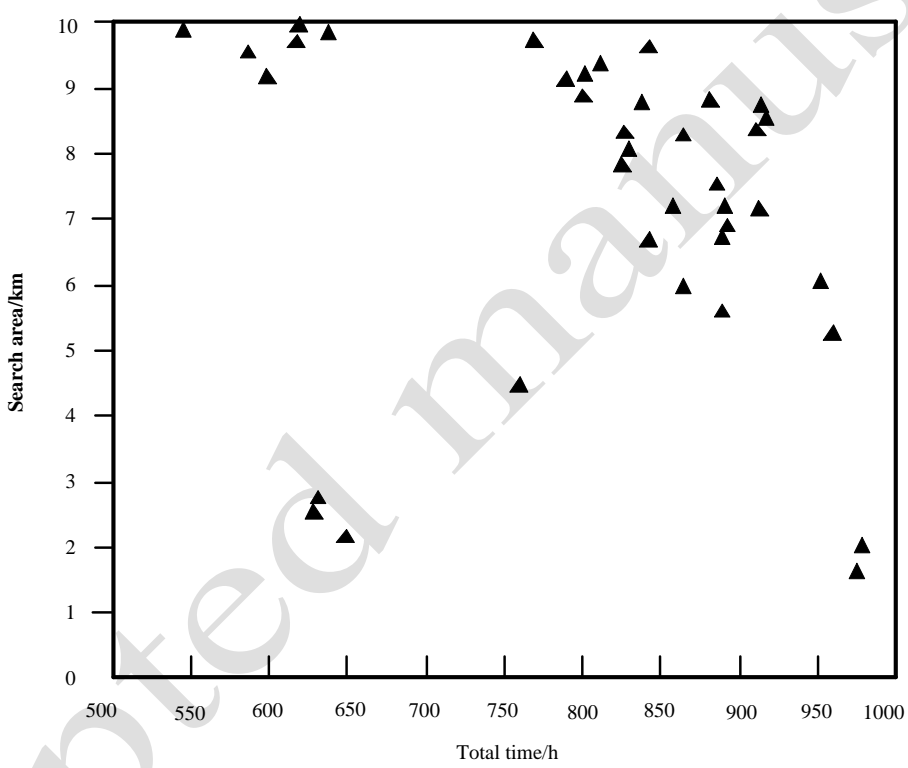

(b) The test results of resource optimal allocation (Viktor and Larisa, 2019) 


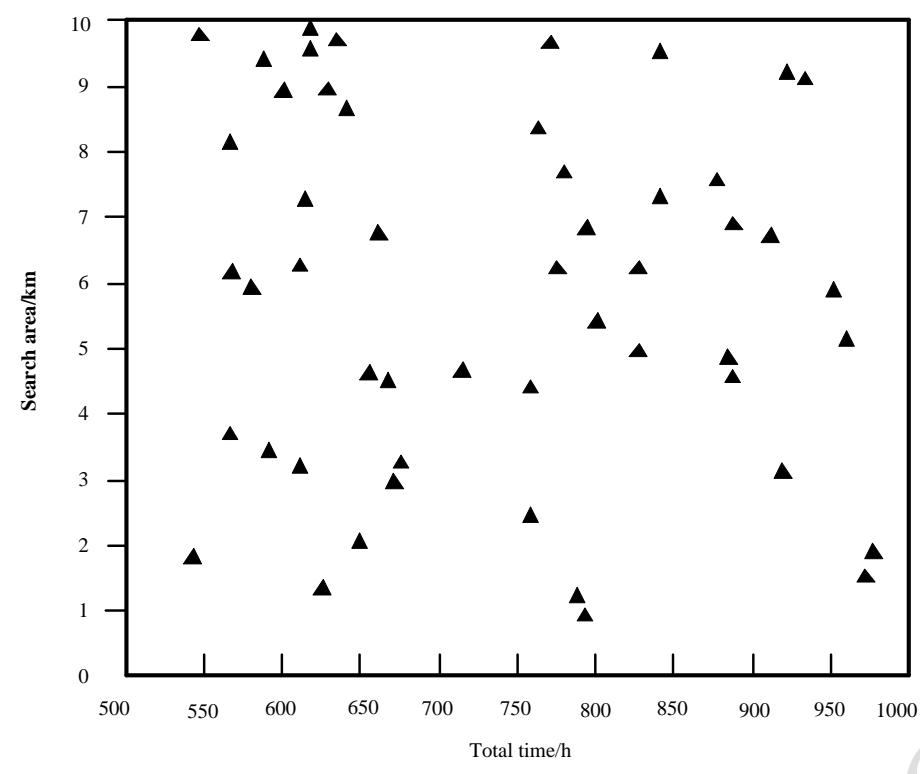

(c) The test results of the proposed method's resource optimization configuration

Figure 5. Experimental test comparison results

According to the experimental test results in Figure 5, under the same search range of sea areas, the distribution uniformity of sea area resources in the traditional method is relatively low. In the case of 600 hours of experiment in Roberto et al. (2018)'s study, the resources of the study showed a trend of dense distribution, followed by the extreme of no distribution of resources. Similar problems also appeared in Viktor and Larisa (2019)'s study. In the first 800 hours of the experiment, resources could not be effectively allocated, while in the second half of the experiment, resource density appeared (Shen et al., 2017; Yunos et al., 2017). In contrast, the proposed method is more uniform in resource analysis and better in resource allocation during the whole experiment. It can be seen that the proposed method has a strong global search capability and a variety of regional configurations.

Based on the above experimental results, the following experiments were conducted to further verify the packet loss index of the research method. In the experiment, Roberto et al. (2018) and Viktor and Larisa (2019)'s studies were used as the experimental group for comparison with the proposed method. Three methods are used to test the packet loss rate of resource allocation in the experimental test area. The smaller the packet loss rate, the better the resource integrity, that is, the better the effect of resource allocation.

Assuming that the loss rate of sea area resource reserve base node $\mathrm{P}$ is $g_{\text {lossi }}$ and the total amount of resources is $R_{i}$ under the condition of time $\mathrm{T}$ and the allocation amount of resources $F$, formula (20) can be obtained:

$$
g_{\text {lossi }}=\frac{R_{i}-F}{R_{i}} \times 100 \%
$$

The specific comparative experimental results are shown in Figure 6. 


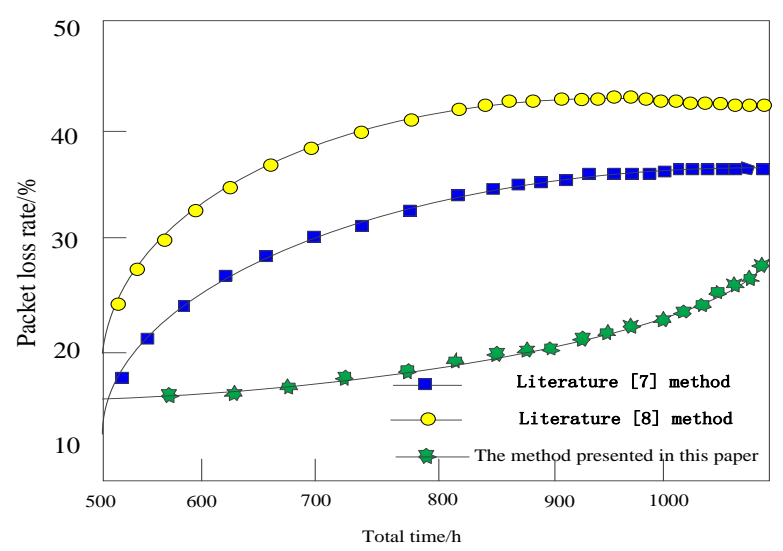

Figure 6. Packet loss rate comparison chart

As shown in Figure 6, the packet loss rate of traditional methods is high in resource allocation, and reaches a high level when the experiment is carried out for 900 hours. The packet loss rate in Roberto et al. (2018)'s study is about $34 \%$, and that in Viktor and Larisa (2019)'s study is about $41 \%$. In this experiment, the packet loss rate of the proposed method is about $25 \%$, which is significantly lower than the other two traditional methods. The experimental results show that in the process of resource allocation, the proposed method has higher resource retention, better resource utilization and better practical application.

\section{Conclusion}

Based on ecological environment protection, this paper proposes a method for optimizing the allocation of sea area resources and realizes the global information search of the sea area where the accident occurred. The reserve resources and accident types in the whole region are effectively coordinated. In the future, it will provide a reasonable plan for optimizing the allocation of sea resources and scientific and technical support for national ecological and environmental protection.

\section{References}

Brauner K., Birami B., Brauner H.A., et al. (2018), Diurnal periodicity of assimilate transport shapes resource allocation and whole plant carbon balance, Plant Journal, 94(5), 776.

Chen Y.Z., He L., Guan Y.L., et al. (2017) Life cycle assessment of greenhouse gas emissions and water-energy optimization for shale gas supply chain planning based on multi-level approach: Case study in Barnett, Marcellus, Fayetteville, and Haynesville shales. Energy Conversion and Management, 134, 382-398.

De La Fuente A., Femenias G., Riera-Palou F., et al. (2018), Subband CQI feedback-based multicast resource allocation in MIMO-OFDMA networks, IEEE Transactions on Broadcasting, 64(4), 846-864.

Dillon L., Sellers C., Underhill V., et al. (2018), The environmental protection agency in the early trump administration: Prelude to regulatory capture, American Journal of Public Health, 108, S89-S94.

Drews, Stefan, Antal, et al. (2018), Challenges in assessing public opinion on economic growth versus environment: considering European and US data, Ecological Economics, 146(3), 265-272.

Dudin B., Ali N.A., Radwan A., et al. (2019), Resource allocation with automated QoE assessment in 5G/B5G wireless systems, IEEE Network, 33(4), 76-81.

Kalpana N. and Ramesh B.B. (2018), Quick resource allocation in heterogeneous networks, Wireless Networks, 24(8), 3171-3188. 
Khamse-Ashari J., Lambadaris I., Kesidis G., et al. (2018), An efficient and fair multi-resource allocation mechanism for heterogeneous servers, IEEE Transactions on Parallel and Distributed Systems, 29(12), 2686-2699.

Khoo S.C., Xue Y.P., Chia M.N., et al. (2019), Recent technologies for treatment and recycling of used disposable baby diapers, Process Safety and Environmental Protection, 123, 116-29.

Liu J., Liu Y. and Wang X. (2019), An environmental assessment model of construction and demolition waste based on system dynamics: A case study in Guangzhou. Environmental Science and Pollution Research International.

Luciano B., Sonia S., Pierpaolo R., et al. (2018), Nature protection areas of europe are insufficient to preserve the threatened beetle Rosalia Alpina (Coleoptera: Cerambycidae): Evidence from species distribution models and conservation gap analysis, Ecological Entomology, 43(192), 203.

Ojaveer H., Neuenfeldt S., Dierking J., et al. (2018), Sustainable use of Baltic Sea resources, ICES Journal of Marine Science, (7), 7.

Roberto P., Pasqualina P., Antonio P., et al. (2018), Multiobjective testing resource allocation under uncertainty, IEEE Transactions on Evolutionary Computation, 22(3), 347-362.

Scott A., Harevey C., Feltzmann H., et al. (2018), Resource allocation and rationing in nursing care: A discussion paper, Biochemistry, 26(4), 12229-12239.

Shen Y., Mi W.J. and Zhang Z.W. (2017), A positioning lockholes of container corner castings method based on image recognition, Polish Maritime Research, 24, 95-101.

Viktor D. and Larisa. (2019), Studying long-term variations in black-sea ecosystem based on the assimilation of remote sensing data in a numerical model, Water Resources, (1), 65-75.

Wen F.H., Xu L.H., Chen B., et al. (2019), Heterogeneous institutional investors, short selling and stock price crash risk: Evidence from China, Emerging Markets Finance and Trade, 1-14.

Ye Z., Hu C., He L., et al. (2020), The dynamic time-frequency relationship between international oil prices and investor sentiment in China: A wavelet coherence analysis, Energy Journal, 41(5).

Yu D., Mao Y., Gu B., et al. (2020). A new LQG optimal control strategy applied on a hybrid wind turbine/solid oxide fuel cell/ in the presence of the interval uncertainties. Sustainable Energy, Grids and Networks, 21, 100296.

Yunos F.H.M., Nurfarahana M.N., Hajjar H.W.J., et al. (2017), Harvesting of microalgae (Chlorella Sp.) from aquaculture bioflocs using an environmental-friendly chitosan-based bio-coagulant, International Biodeterioration \& Biodegradation, 124, 243-49.

Zhang X.H., Tomsovic K. and Dimitrovski, A. (2018), Optimal allocation of series FACTS devices in large scale systems, Iet Generation Transmission \& Distribution 12(8), 1889-1896.

Zuo X., Dong M., Gao F., et al. (2020), The modeling of the electric heating and cooling system of the integrated energy system in the coastal area, Journal of Coastal Research, 103, 1022. 